\title{
P-Selectin/ICAM-1 Double Mutant Mice: Acute Emigration of Neutrophils into the Peritoneum Is Completely Absent but Is Normal into Pulmonary Alveoli
}

Daniel C. Bullard, * Lan Qin, ${ }^{\mathbf{5}}$ Isabel Lorenzo, * ${ }^{*}$ William M. Quinlin, ${ }^{5}$ Nicholas A. Doyle, ${ }^{\mathbf{S}}$ Roland Bosse,"

Dietmar Vestweber," Claire M. Doerschuk, $\$$ and Arthur L. Beaudet**

${ }^{*}$ Department of Molecular and Human Genetics, Baylor College of Medicine, and ${ }^{\ddagger}$ Howard Hughes Medical Institute, Houston, Texas $77030 ;{ }^{8}$ Herman B. Wells Center for Pediatric Research and the Section of Pulmonology, Department of Pediatrics, Indiana University, Indianapolis, Indiana 46202; and "Hans-Spemann Laboratory, Max-Planck Institut für Immunobiologie, Freiburg, Germany 79103

\begin{abstract}
Neutrophil emigration during an inflammatory response is mediated through interactions between adhesion molecules on endothelial cells and neutrophils. P-Selectin mediates rolling or slowing of neutrophils, while intercellular adhesion molecule-1 (ICAM-1) contributes to the firm adhesion and emigration of neutrophils. Removing the function of either molecule partially prevents neutrophil emigration. To analyze further the role of P-selectin and ICAM-1, we have generated a line of mice with mutations in both of these molecules. While mice with either mutation alone show a $60-70 \%$ reduction in acute neutrophil emigration into the peritoneum during Streptococcus pneumoniae-induced peritonitis, double mutant mice show a complete loss of neutrophil emigration. In contrast, neutrophil emigration into the alveolar spaces during acute $S$. pneumoniae-induced pneumonia is normal in double mutant mice. These data demonstrate organ-specific differences, since emigration into the peritoneum requires both adhesion molecules while emigration into the lung requires neither. In the peritoneum, P-selectin-independent and ICAM-1-independent adhesive mechanisms permit reduced emigration when one of these molecules is deficient, but P-selectin-independent mechanisms cannot lead to ICAM-1-independent firm adhesion and emigration. (J. Clin. Invest. 1995. 95:1782-1788.) Key words: adhesion • mutant mice $\bullet P$-selectin $\bullet$ intercellular adhesion molecule-1 $\bullet$ neutrophil
\end{abstract}

\section{Introduction}

Leukocyte emigration from the postcapillary venules in response to an inflammatory stimulus requires multiple adhesive interactions in addition to various chemoattractant and activator molecules $(1,2)$. In vivo observations of postcapillary venules using intravital microscopy have identified several distinct phases of leukocyte/endothelial interactions which occur before neutrophil emigration from the vasculature (3-5). In the initial phase, leukocytes marginate to the endothelial cell wall and roll along its surface. A portion of these rolling leukocytes then

Address correspondence to Arthur L. Beaudet, Department of Molecular and Human Genetics, Baylor College of Medicine, One Baylor Plaza, T619, Houston, TX 77030. Phone: 713-798-4795; FAX: 713-798-8515.

Received for publication 21 October 1994 and in revised form 15 December 1994.

J. Clin. Invest.

(C) The American Society for Clinical Investigation, Inc.

0021-9738/95/04/1782/07 \$2.00

Volume 95, April 1995, 1782-1788 firmly adheres to the endothelium, becomes activated, changes shape, and migrates through the endothelial cell junctions into the surrounding tissues. Three families of adhesion molecules which play a significant role in mediating neutrophil/endothelial interactions are the selectins, members of the immunoglobulin superfamily, and the integrins $(1,2,6)$.

The three members of the selectin gene family, L-, E-, and P-selectin, have all been shown to be capable of mediating neutrophil rolling either in vitro or in vivo (7-13). L-Selectin is constitutively expressed on the majority of circulating leukocytes and is shed upon their activation (14-16). P-Selectin is rapidly and transiently expressed on endothelium and platelets after stimulation with activating molecules such as thrombin, histamine, and TNF- $\alpha(17-20)$. E-Selectin is expressed on endothelial cells after stimulation with mediators such as IL-1 and TNF- $\alpha$ and its expression requires new mRNA synthesis (21). The importance of this selectin-mediated neutrophil rolling is illustrated by studies in which blocking of selectin-mediated adhesion (with antibodies or by gene targeting) decreases neutrophil emigration into a particular tissue after an inflammatory stimulus $(1,7,8,16,22)$.

The interactions between the CD11/CD18 integrins expressed on neutrophils (specifically CD11a and CD11b) with endothelial ligands such as intercellular adhesion molecule-1 (ICAM-1), ${ }^{1}$ in the presence of an activator molecule, can contribute to the arrest of neutrophils along the endothelial cell surface $(1,2)$. Activation of these CD18 integrins is associated with both increased avidity and upregulation of expression on the neutrophil cell surface (4). ICAM-1 is constitutively expressed on endothelial cells and can be upregulated at the cell surface by various inflammatory mediators such as IL-1, TNF$\alpha$, endotoxin, and $\gamma$-interferon (23-26). Blocking or loss of expression of CD11a, CD11b, or ICAM-1 can reduce the capability of neutrophils to adhere to the endothelium and subsequently reduces neutrophil emigration $(1,4,27,28)$. Transmigration of neutrophils between the endothelial cell junctions requires both adhesive interactions and a chemotactic gradient (1). Transmigration can be significantly inhibited by antibodies to CD18, ICAM-1, and platelet endothelial cell adhesion molecule-1, another member of the immunoglobulin superfamily ( 1 , $4,29,30$ ). Platelet endothelial cell adhesion molecule-1 is expressed on the intercellular junctions of endothelial cells, platelets, and leukocytes (31).

Inhibiting adhesive interactions at either the rolling, firm adhesion, or transmigration steps can partially reduce neutrophil emigration. However, neutrophil emigration in vivo is not completely blocked using these strategies, suggesting that redundancy occurs at each step. To analyze further the role of adhe-

1. Abbreviations used in this paper: EVA, extravascular albumin; ICAM-1, intercellular adhesion molecule-1; RBC, red blood cells. 
sion molecules in neutrophil emigration we have generated a line of P-selectin- and ICAM-1-deficient mice. We have used these mice to study emigration of neutrophils into the peritoneal cavity and into the pulmonary alveolar space in response to Streptococcus pneumoniae.

\section{Methods}

$P$-Selectin gene targeting in embryonic stem cells. A mouse cDNA clone (32) was used to screen a $129 / \mathrm{Sv}$ genomic DNA library (Stratagene, La Jolla, CA), and the genomic clones were characterized for preparation of the P-selectin targeting vector. Intron-exon boundaries were assumed to be conserved between mouse and human (33). Based on the mouse cDNA sequence, PCR primer pairs were selected within each exon to yield a product which could be used to localize the exon within genomic DNA fragments. The construct for homologous recombination was prepared as shown in Fig. 1. The AB2.1 embryonic stem cell line (34, 35 ) (provided by Allan Bradley, Baylor College of Medicine) was electroporated with $25 \mu \mathrm{g} \mathrm{ml}^{-1}$ linearized vector as described $(35,36)$. Digestion with EcoRV was used to identify homologous recombinants on Southern blots hybridized with the probe indicated in Fig. $1 \mathrm{~A}$. Several clones were isolated which correctly targeted the P-selectin gene, and injection of one of these clones into C57BL/6J embryos resulted in germline transmission.

RNA analyses. RNA was isolated from wild-type, heterozygote, and homozygous mutant animals $2 \mathrm{~h}$ after intraperitoneal injection with 50 $\mu \mathrm{g}$ of LPS from Salmonella typhosa (Difco Laboratories Inc., Detroit, MI) to induce expression of the P-selectin gene (32). A primer specific for exon 6 (5'-ACAGGTTGGCAGTGGTTCAC-3') was used to prime first strand cDNA followed by PCR amplification using this primer and an exon 2 specific primer ( $5^{\prime}$-GCTGGCTGCCCAAAAGGTT-3'). The PCR products were then visualized by ethidium bromide staining on agarose gels. PCR amplification from wild-type P-selectin RNA results in a 953-bp fragment, while amplification from mutant transcripts, which do not contain exons 3-5, results in a 271-bp fragment.

Immunohistochemistry. The lungs from mutant and wild-type mice were inflated using 50\% OCT compound (Miles, Inc., Elkhart, IN). PSelectin was localized on frozen sections using either the rat monoclonal antimurine P-selectin antibody RB40.34.4 $(0.01 \mathrm{mg} / \mathrm{ml}$ ) (Bosse, R., and D. Vestweber, manuscript in preparation $)$, rat $\operatorname{IgG}(0.01 \mathrm{mg} / \mathrm{ml}$; Sigma Immunochemicals, St. Louis, MO), or Tris buffer as the primary antibody, followed by localization using avidin-biotin-alkaline phosphatase complexes and a substrate containing new fuchsin. The sections were counterstained with hematoxylin.

Peripheral blood leukocyte counts. Peripheral blood was collected from the retro-orbital venous plexus with EDTA anticoagulation from mutant and wild-type animals. All animals were 6-8 wk old, and approximately equal numbers of males and females were analyzed. PSelectin and P-selectin/ICAM-1 mutant mice were from a mixed 129/ $\mathrm{Sv} \times$ C57BL/6J background; ICAM-1 mutant mice were from a fifth generation backcross with C57BL/6J. Initially, two separate groups of control mice were used for these studies $(\mathrm{C} 57 \mathrm{BL} / 6 \mathrm{~J} \times 129 / \mathrm{Sv}$ and C57BL/6J); since no significant differences were found between these control groups, the results were combined. Total leukocyte counts and differentials were determined using an $\mathrm{H}^{*} 1$ Hematology analyzer (Technicon, Tarrytown, NY) calibrated for analysis of murine samples. One-way analyses of variance were used to compare the leukocyte counts and differentials between each group. When a significant overall difference was found, multiple contrasts were used with a Bonferroni adjustment to determine which groups were significantly different.

S. pneumoniae-induced peritonitis. Mice were anesthetized using ketamine hydrochloride (80-100 mg/kg intramuscularly) and acepromazine maleate $(5-8 \mathrm{mg} / \mathrm{kg}$ intramuscularly). Iodinated albumin $(0.2-$ $0.3 \mu \mathrm{Ci} /$ mouse) was given intravenously, followed $15 \mathrm{~min}$ later by intraperitoneal injection of $S$. pneumoniae $\left(0.2 \mathrm{ml} /\right.$ mouse of $5 \times 10^{9}$ $\mathrm{CFU} / \mathrm{ml}$ ). After either 2 or $4 \mathrm{~h}$, the peritoneal space was lavaged with 3 aliquots of $5 \mathrm{ml}$ phosphate-buffered saline. Neutrophil emigration into the peritoneum was quantitated by performing cell counts and differen- tials in the peritoneal lavage fluid using a hemocytometer and Wrightstained cytospin preparations. The accumulation of ${ }^{125} \mathrm{I}$-albumin in the peritoneum, a measure of edema formation, was calculated as the ${ }^{125} \mathrm{I}$ albumin counts in the lavage fluid divided by the total ${ }^{125}$ I-albumin counts recovered in the mouse minus the tail. Statistical analyses were performed as described above. For calculation of the reduction in neutrophil emigration or edema formation, the value for mice not receiving bacteria was first subtracted from the observed value.

$S$. pneumoniae-induced pneumonia. Mice were anesthetized (as described above) and then were given an intravenous injection of iodinated albumin $(0.2-0.3 \mu \mathrm{Ci} /$ mouse $)$, followed $15 \mathrm{~min}$ later by intratracheal instillation of $S$. pneumoniae $\left(0.05 \mathrm{ml} /\right.$ mouse of $5 \times 10^{9} \mathrm{CFU} /$ $\mathrm{ml}$ ) containing $5 \%$ colloidal carbon to mark its distribution in the distal lung. ${ }^{51}$ Chromium-labeled murine red blood cells $(\mathrm{RBC})$ were injected after $5 \mathrm{~h}, 58 \mathrm{~min}$ to mark the intravascular blood volume. At $6 \mathrm{~h}$, a blood sample was taken from the inferior vena cava, the thoracic cavity was rapidly opened, the base of the heart was tied to prevent loss of blood from the pulmonary microvasculature, the thoracic organs were removed, and the lungs were fixed using intratracheal instillation of 4.5\% glutaraldehyde in phosphate buffer. Any leakage of fixative was collected in scintillation vials. After fixation overnight, the heart and mediastinal tissues were removed, and the lungs, blood, and plasma were counted. The pulmonary extravascular albumin was calculated as: $\mathrm{EVA}=$ total ${ }^{125} \mathrm{I}$-albumin volume in lungs - intravascular ${ }^{125} \mathrm{I}$-albumin volume where

total ${ }^{125} \mathrm{I}$-albumin volume in lungs $=\frac{{ }^{125} \mathrm{I} \text {-albumin in lungs }}{{ }^{125} \mathrm{I} \text {-albumin } / \mathrm{g} \text { plasma }}$

and

intravascular ${ }^{125} \mathrm{I}$-albumin $=\frac{{ }^{51} \mathrm{Cr}-\mathrm{RBC} \text { in lung }}{{ }^{51} \mathrm{Cr}-\mathrm{RBC} / \mathrm{g} \text { blood }} \times(1$-hematocrit $)$.

The EVA is expressed as microliters of plasma equivalents. Neutrophil emigration was evaluated histologically using paraffin-embedded sections by counting the number of neutrophils per 100 alveoli on randomly selected fields containing colloidal carbon. Statistical analyses were performed as described above.

\section{Results}

Generation of $P$-selectin and P-selectin/ICAM-1 double mutant mice. P-Selectin mutant mice were generated by gene targeting using a replacement vector designed to delete exons 3-5 (Fig. 1 A) $(35,36)$. Deletion of a $4.5-\mathrm{kb}$ region containing these exons was confirmed by Southern blotting in mice (Fig. $1 B$ ). Analysis by RT-PCR demonstrated normal mRNA in wild-type animals and a shortened mRNA consistent with deletion of exons 3-5 in mutant animals (Fig. $1 C$ ). A monoclonal rat antibody against $\mathrm{P}$-selectin was used to analyze expression of $P$-selectin as assessed by immunohistochemical staining of the lung microvasculature (Fig. $1, D$ and $E$ ). Antibody staining was detected in wild-type animals on endothelial cells and on platelets inside the vessel; mutant animals showed loss of expression on both endothelium and platelets. P-Selectin mutant mice were bred to mice containing a mutation in the ICAM-1 gene (27) to generate double homozygotes. P-Selectin/ICAM1 double homozygotes were viable, fertile, and without obvious phenotypic abnormalities.

Peripheral blood leukocyte counts. Examination of circulating leukocyte counts revealed a significant increase in the number of neutrophils in P-selectin, ICAM-1, and P-selectin/ICAM1 double mutants when compared with wild-type mice of similar genetic background (Table I). The neutrophil counts in the double mutant mice were similar to those in ICAM-1 mutants but were significantly higher than those in the P-selectin mu- 
CONSTRUCT
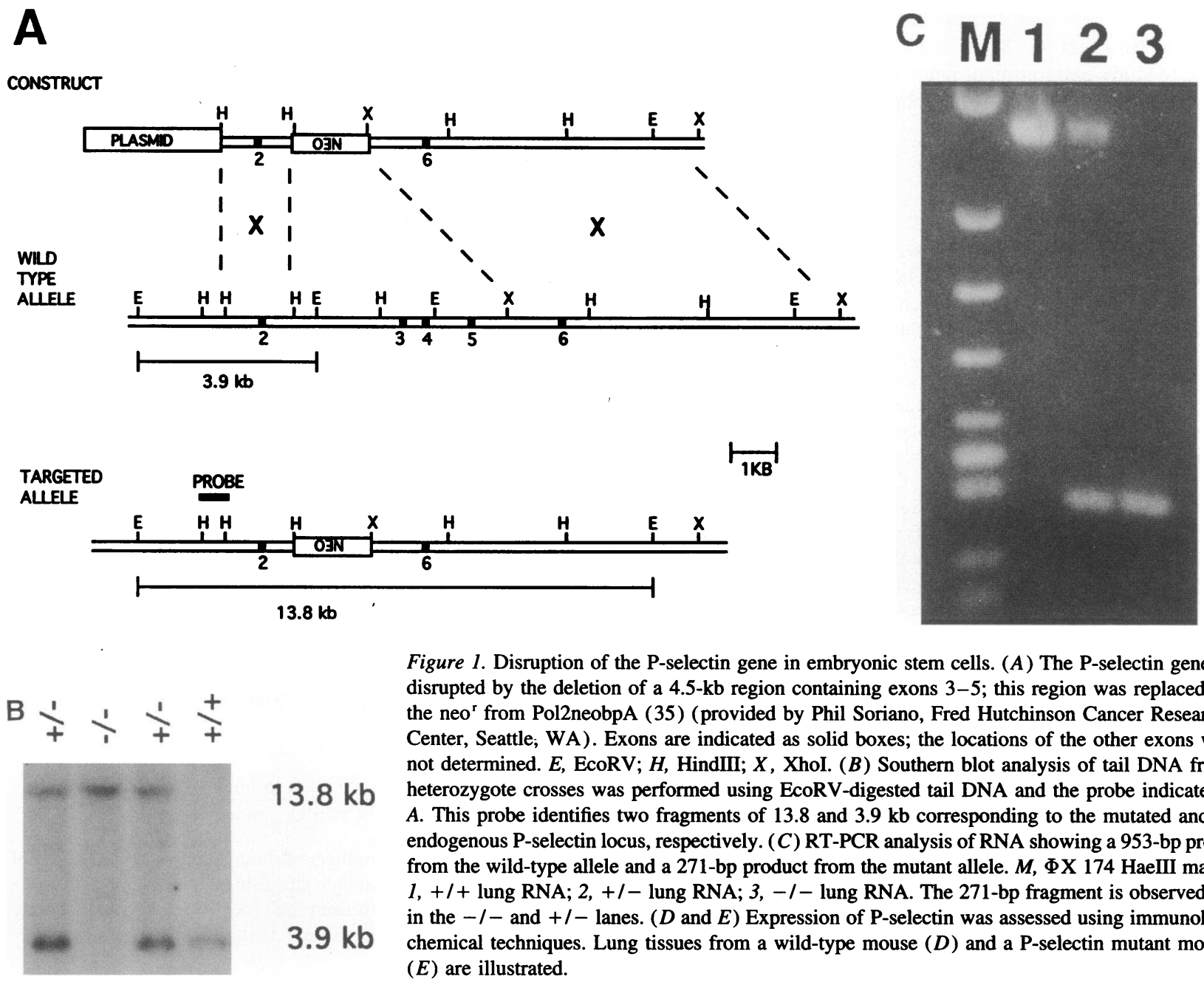

Figure 1. Disruption of the P-selectin gene in embryonic stem cells. $(A)$ The P-selectin gene was disrupted by the deletion of a 4.5-kb region containing exons 3-5; this region was replaced with the neo ${ }^{r}$ from Pol2neobpA (35) (provided by Phil Soriano, Fred Hutchinson Cancer Research Center, Seattle, WA). Exons are indicated as solid boxes; the locations of the other exons were not determined. $E$, EcoRV; $H$, HindIII; $X$, XhoI. $(B)$ Southern blot analysis of tail DNA from

$13.8 \mathrm{~kb}$ heterozygote crosses was performed using EcoRV-digested tail DNA and the probe indicated in $A$. This probe identifies two fragments of 13.8 and $3.9 \mathrm{~kb}$ corresponding to the mutated and endogenous P-selectin locus, respectively. $(C)$ RT-PCR analysis of RNA showing a 953-bp product from the wild-type allele and a 271-bp product from the mutant allele. $M, \Phi$ X 174 HaeIII marker; $1,+/+$ lung RNA; $2,+/-$ lung RNA; 3, - /- lung RNA. The 271-bp fragment is observed only in the $-/-$ and $+/-$ lanes. ( $D$ and $E$ ) Expression of P-selectin was assessed using immunohisto$3.9 \mathrm{~kb}$ chemical techniques. Lung tissues from a wild-type mouse $(D)$ and a P-selectin mutant mouse $(E)$ are illustrated.

tants. The circulating lymphocyte and monocyte counts were increased only in the ICAM-1 and the P-selectin/ICAM-1 mutants and not in the P-selectin mutants. The exact mechanism for the increased circulating leukocyte counts in the mutants when compared with wild-type mice is not known, but this phenomenon is also observed in both CD18 mutant mice and in patients with moderate or severe leukocyte adhesion deficiency $(28,37-39)$.

Neutrophil emigration and edema formation during $S$. pneumoniae-induced peritonitis. Mice with single mutations in the P-selectin and ICAM-1 genes were previously shown to display an impaired neutrophil response during thioglycollate-induced peritonitis $(7,27)$. To address whether the combined deficiency of both P-selectin and ICAM-1 would result in a more severe reduction in neutrophil emigration than the loss of each single gene, we studied the acute inflammatory process during peritonitis for each genotype. Peritonitis was induced in control, Pselectin, ICAM-1, and P-selectin/ICAM-1 homozygous mutant mice by intraperitoneal instillation of $S$. pneumoniae, and neutrophil emigration and edema formation were evaluated after 2 or $4 \mathrm{~h}(40)$.

As shown in Table II, neutrophil emigration into the peritoneum in P-selectin mutant mice was reduced by $61 \%$ at $2 \mathrm{~h}$ and $69 \%$ at $4 \mathrm{~h}$ compared with wild-type mice, although edema formation was not altered. ICAM-1 mutant mice showed a $64 \%$ reduction in neutrophil emigration at $4 \mathrm{~h}$, with no significant change in ${ }^{125} \mathrm{I}$-albumin accumulation. However, when mice deficient in both P-selectin and ICAM-1 were examined, stimulated neutrophil emigration was completely absent. Edema formation was similar at $2 \mathrm{~h}$ to wild-type animals, but was reduced at $4 \mathrm{~h}$. The accumulation of mononuclear leukocytes was not significantly different in any group.

Neutrophil emigration and edema formation during S. pneumoniae-induced pneumonia. Previous studies investigating neutrophil emigration during pneumonia have shown that the inflamed site is recognized by the circulating neutrophils between 1 and $2 \mathrm{~h}$ after intrabronchial instillation of organisms and that large numbers neutrophils have emigrated into the alveolar space by 4-8 h (41). To examine the effect of combined P-selectin and ICAM-1 deficiency on neutrophil recruitment and edema formation in the lung, pneumonia was induced in mutant and wild-type mice by intratracheal instillation of $S$. pneumoniae $(40,42)$. After $6 \mathrm{~h}$, wild-type mice developed an acute inflammatory response within the bronchioles and alveolar space (Table III). In contrast to the results obtained in the peritoneum, combined deficiency of P-selectin and ICAM-1 did not cause a reduction in neutrophil recruitment into the alveolar space or in edema formation (Table III).

\section{Discussion}

This study investigated the roles of P-selectin and ICAM-1 in the acute inflammatory response induced by $S$. pneumoniae 

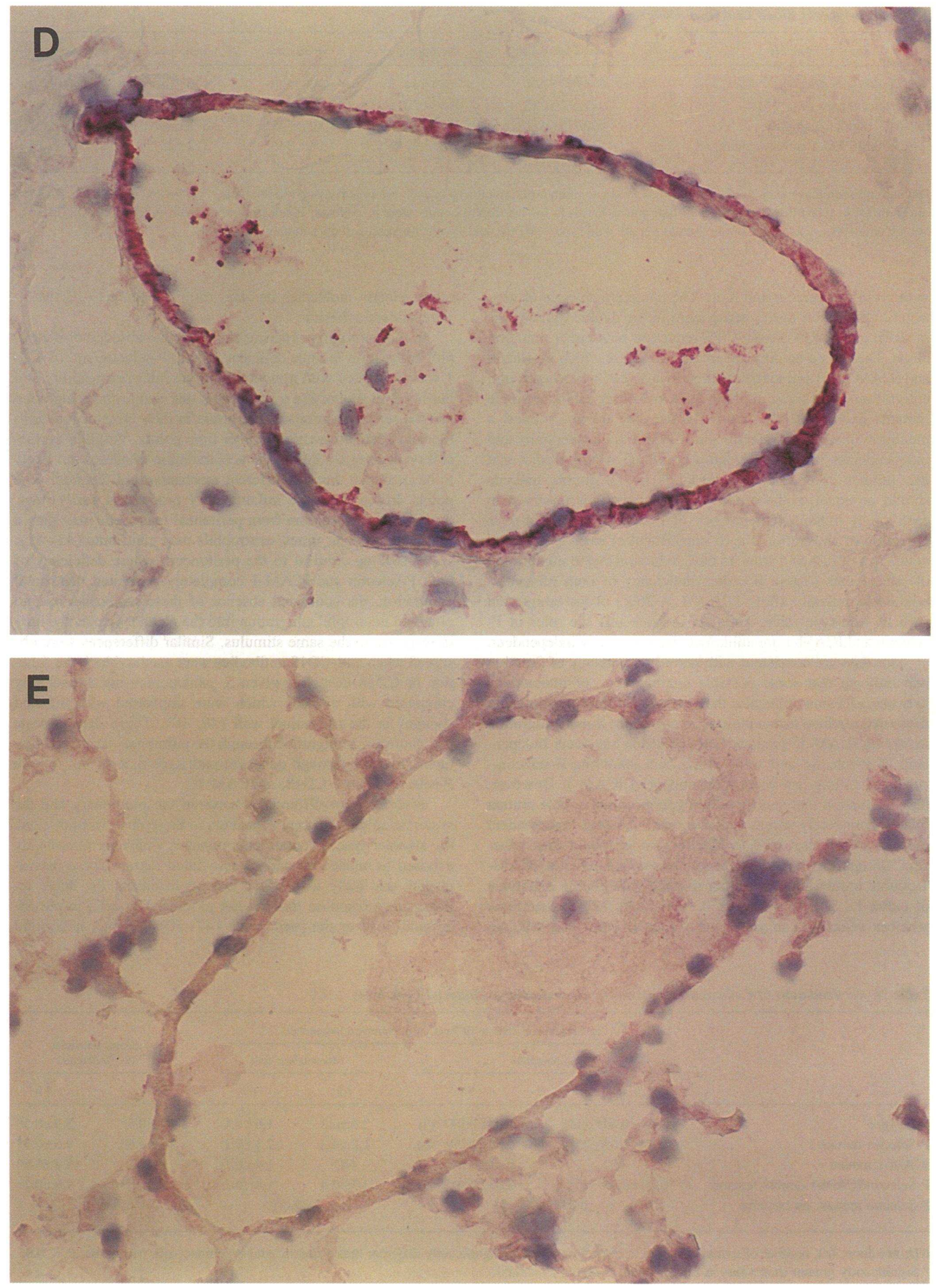

Figure 1 (Continued) 
Table I. Peripheral Blood Leukocyte Counts

\begin{tabular}{lccccc}
\hline \multicolumn{1}{c}{ Animals } & Total leukocytes & Neutrophils & Lymphocytes & Monocytes & Platelets $\left(\times 10^{5}\right)$ \\
\hline Wild-type $(n=46)$ & $6207 \pm 244$ & $689 \pm 44$ & $5143 \pm 220$ & $170 \pm 13$ & $8.9 \pm 0.3$ \\
P-Selectin mutant $(n=15)$ & $7817 \pm 657$ & $1653 \pm 201^{*}$ & $5620 \pm 478$ & $233 \pm 16$ & $9.1 \pm 0.3$ \\
ICAM-1 mutant $(n=12)$ & $12079 \pm 451^{*}$ & $3273 \pm 545^{*}$ & $8068 \pm 545^{*}$ & $373 \pm 34^{*}$ & $10.9 \pm 0.8$ \\
P-Selectin/ICAM-1 double mutant $(n=23)$ & $11140 \pm 585^{*}$ & $3265 \pm 271^{*}$ & $7159 \pm 346^{*}$ & $312 \pm 25^{*}$ & $7.9 \pm 0.4$ \\
\hline
\end{tabular}

Data are presented as mean numbers $/ \mu \mathrm{l} \pm \mathrm{SEM}$, and the number of animals $(n)$ in each group is provided in the table. ${ }^{*}$ Adjusted $P$ value significantly different $(P<0.05)$ than value in wild-type mice. $P$ values for neutrophil counts were as follows: $P$-selectin versus wild-type $=0.011$; ICAM-1 versus wild-type $<0.0004$; double mutant versus wild-type $<0.004$; and P-selectin versus double mutant $<0.0004$.

within the peritoneum and lung. The complete absence of neutrophil emigration in the peritoneum in the double mutant was in sharp contrast to the $60-70 \%$ reduction with either mutation alone. These data do not support a paradigm in which P-selectin and ICAM-1 act in independent pathways leading to neutrophil emigration, since the sum of the reduction observed in the single mutants exceeds $100 \%$. Similarly the data do not support a paradigm in which P-selectin and ICAM-1 act sequentially and independently in the same pathway, which would predict that the number of emigrated neutrophils in the double mutants should be equal to the product of the reductions observed in each single mutant. If deficiency of P-selectin results in $69 \%$ reduction of emigration due to impairment of early events, and deficiency of ICAM-1 leads to $64 \%$ reduction due to impairment of later events (Table II), then deficiency of both molecules would theoretically allow $11 \%(31 \times 36 \%)$ of the emigration seen in wild-type mice. The data indicate that the roles of $\mathrm{P}$ selectin and ICAM-1 are unlikely to be completely independent.

Our data are consistent with partial redundancy of function and indicate that some possible combinations of interactions between adhesion molecules that mediate neutrophil rolling and those that mediate firm adhesion do not occur. Some emigration involving ICAM-1-mediated firm adhesion can occur independent of P-selectin and some emigration involving P-selectinmediated rolling can occur independent of ICAM-1. However, the observation that neutrophil emigration in the double mutant mice is completely absent indicates that P-selectin-independent mechanisms cannot lead to ICAM-1-independent firm adhesion. Comparing the inflammatory process in P-selectin/ICAM1 double mutant mice with that in mice with double mutations of either L- or E-selectin and ICAM-1 will help to determine whether selectins can substitute for each other and whether other selectin molecules mediate rolling leading to ICAM-1independent adhesion.

In the peritonitis experiments, complete absence of neutrophil emigration in mice deficient in both P-selectin and ICAM1 was associated with a reduction in vascular permeability at 4 but not $2 \mathrm{~h}$, supporting a hypothesis that neutrophil emigration and the release of products important in their effector functions mediate edema formation at later time points. Vascular permeability changes leading to the accumulation of edema are likely to be mediated through different mechanisms at different time points during the acute inflammatory process; at early times, the release of histamine from peritoneal mast cells may play a role, while at later times, neutrophils may contribute (43-45).

In striking contrast to the peritoneum where deficiency of both P-selectin and ICAM-1 completely prevented neutrophil emigration, the combined absence of these molecules had no effect on neutrophil emigration into the parenchyma of the lung in response to the same stimulus. Similar differences were observed when anti-CD18 antibodies were used to block the function of CD18 in rabbits given $S$. pneumoniae intrabronchially compared with animals which were implanted with infected sponges in the abdominal wall $(40,46)$. These data indicate that neutrophil emigration through the pulmonary microvasculature can occur through adhesion pathways that do not require P-selectin, CD11/CD18, or ICAM-1.

Several major differences between the pulmonary and the systemic circulation may contribute to these observations. First, the alveolar spaces contain macrophages which are chronically exposed to inhaled air and its associated toxins. These macrophages are likely to produce mediators during the acute inflammatory response that are not produced by cells in the abdominal wall or the peritoneum (47-50). Second, neutrophil

Table II. Accumulation of Cells and Edema during S. pneumoniae-induced Peritonitis

\begin{tabular}{|c|c|c|c|c|c|c|}
\hline & \multicolumn{4}{|c|}{ Accumulation of cells $\times 10^{-5}$ per $\mathrm{ml}$ of peritoneal lavage fluid } & \multirow{2}{*}{\multicolumn{2}{|c|}{$\begin{array}{l}\text { Edema formation } \\
\text { (\% }{ }^{125} \mathrm{I} \text {-albumin) }\end{array}$}} \\
\hline & \multicolumn{2}{|c|}{ Neutrophils } & \multicolumn{2}{|c|}{ Mononuclear cells } & & \\
\hline & $2 \mathrm{~h}$ & $4 \mathrm{~h}$ & $2 \mathrm{~h}$ & $4 \mathrm{~h}$ & $2 \mathrm{~h}$ & $4 \mathrm{~h}$ \\
\hline Wild-type & $0.44 \pm 0.04 *(11)$ & $1.04 \pm 0.08 *(9)$ & $2.5 \pm 0.3$ & $1.6 \pm 0.1$ & $4.0 \pm 0.5^{*}$ & $5.3 \pm 0.5^{*}$ \\
\hline P-Selectin mutant & $0.20 \pm 0.05^{\ddagger}(5)$ & $0.36 \pm 0.09^{\ddagger}(8)$ & $1.2 \pm 0.3$ & $2.1 \pm 0.2$ & $3.2 \pm 0.6^{*}$ & $4.5 \pm 0.3 *$ \\
\hline ICAM-1 mutant & ND & $0.41 \pm 0.04^{\ddagger}$ & ND & $1.9 \pm 0.1$ & ND & $5.4 \pm 0.9 *$ \\
\hline P-Selectin/ICAM-1 double mutant & $0.06 \pm 0.01^{\ddagger}$ & $0.03 \pm 0.01^{\ddagger}$ & $2.5 \pm 0.4$ & $1.4 \pm 0.2$ & $4.0 \pm 1.5^{*}$ & $1.9 \pm 0.2^{\ddagger}$ \\
\hline P-Selectin mutant, no bacteria & \multicolumn{2}{|c|}{$0.05 \pm 0.00^{\ddagger}(4)$} & \multicolumn{2}{|c|}{$2.2 \pm 0.1$} & \multicolumn{2}{|c|}{$0.4 \pm 0.2$} \\
\hline
\end{tabular}

$N D$, not done; $(n)$, number of animals studied at each time point. ${ }^{\ddagger}$ Significantly different than value in wild-type mice with peritonitis, $P<0.05$. * Significantly greater than value in mice without bacteria, $P<0.05$. 
Table III. Accumulation of Neutrophils and Edema during S. pneumoniae-induced Pneumonia

\begin{tabular}{lcc}
\hline & $\begin{array}{c}\text { Neutrophils/ } \\
100 \text { alveoli }\end{array}$ & $\begin{array}{c}\text { Extravascular } \\
\text { albumin }\end{array}$ \\
\hline Wild-type (5) & $626 \pm 30^{*}$ & $60 \pm 7 *$ \\
P-Selectin/ICAM-1 double mutant (5) & $687 \pm 26^{*}$ & $56 \pm 3^{*}$ \\
Wild-type, no bacteria (5) & $1.4 \pm 0.6$ & $29 \pm 3$ \\
\hline
\end{tabular}

The data are expressed as mean \pm SEM, and the numbers of animals ( $n$ ) in each group are provided in the table. * Significantly greater than in wild-type mice that received no bacteria, $P<0.05$.

emigration in the systemic circulation occurs through the postcapillary venules while emigration in the lung occurs at least in part through the capillary bed (51). The smaller diameter of the lung capillary segments in comparison with the postcapillary venules forces most neutrophils to deform to pass through these vessels, and rolling is very unlikely to occur due to spatial constraints (52). Finally, the expression of these adhesion molecules varies in the pulmonary vasculature. Although ICAM-1 is constitutively expressed on the pulmonary capillary endothelium, it is not upregulated in response to $S$. pneumoniae (53). Light immunohistochemical studies identified constitutive expression of P-selectin only in arteries and venules, but not in capillaries (Fig. 1 D). Recent studies showed P-selectin is not upregulated on the capillary bed in response to $S$. pneumoniae, although Mulligan et al. (54) showed that P-selectin can be briefly expressed on these cells in response to cobra venom factor. The adhesion molecules that mediate neutrophil emigration in response to $S$. pneumoniae in the lung remain to be determined. It is possible that compensatory upregulation of alternative adhesion pathways occurs in the lung in mutant animals. Alternatively, because of the geometric constraints, neutrophils may be in close contact with the endothelium during transit through the capillary bed and may not require the same adhesive mechanisms as other organs.

\section{Acknowledgments}

We thank Wayne Smith and Klaus Ley for critical reading of the manuscript and Leigh Anne Hurley and Lori Graham for technical assistance.

This work was supported by a fellowship (D. C. Bullard) and research grants (C. M. Doerschuk and A. L. Beaudet) from the National Institutes of Health and by a Career Investigator Award from the American Lung Association (C. M. Doerschuk).

\section{References}

1. Albelda, S. M. C. W. Smith, and P. A. Ward. 1994. Adhesion molecules and inflammatory injury. FASEB (Fed. Am. Soc. Exp. Biol.) J. 8:504-512.

2. Springer, T. A. 1994. Traffic signals for lymphocyte recirculation and leukocyte emigration: the multistep paradigm. Cell. 76:301-314.

3. Atherton, A., and G. V. R. Born. 1972. Quantitative investigations of the adhesiveness of circulating polymorphonuclear leucocytes to blood vessel walls. J. Physiol. (Lond.). 222:447-474.

4. Harlan, J. M., and D. Y. Liu. 1992. Adhesion: Its Role in Inflammatory Disease. W. H. Freeman and Company, New York. 202 pp.

5. Arfors, K., C. Lundberg, L. Lindbom, K. Lundberg, P. G. Beatty, and J. M Harlan. 1987. A monoclonal antibody to the membrane glycoprotein complex CD18 inhibits polymorphonuclear leukocyte accumulation and plasma leakage in vivo. Blood. 69:338-340.

6. Bevilacqua, M. P., and R. M. Nelson. 1993. Selectins. J. Clin. Invest. 91:379-387.

7. Mayadas, T. N., R. C. Johnson, H. Rayburn, R. O. Hynes, and D. D.
Wagner. 1993. Leukocyte rolling and extravasation are severely compromised in P selectin-deficient mice. Cell. 74:541-554.

8. Arbonés, M. L. D. C. Ord, K. Ley, H. Ratech, C. Maynard-Curry, G. Otten, D. J. Capon, and T. F. Redder. 1994. Lymphocyte homing and leukocyte rolling and migration are impaired in L-selectin-deficient mice. Immunity. 1:247260.

9. Ley, K., P. Gachtgens, C. Kennie, M. S. Singer, L. A. Lasky, and S. D. Rosen. 1991. Lectin-like cell adhesion molecule 1 mediates leukocyte rolling in mesenteric venules in vivo. Blood. 77:2553-2555.

10. von Adrian, U. H., J. D. Chambers, L. M. McEvoy, R. F. Bargatze, K.-E. Arfors, and E. C. Butcher. 1991. Two-step model of leukocyte-endothelial cell interaction in inflammation: distinct roles for LECAM-1 and the leukocyte $\beta 2$ integrins in vivo. Proc. Natl. Acad. Sci. USA. 88:7538-7542.

11. Lawrence, M. B., and T. A. Springer. 1991. Leukocytes roll on a selectin at physiologic flow rates: distinction from and prerequisite for adhesion through intergrins. Cell. 65:859-873.

12. Ley, K., T. F. Tedder, and G. S. Kansas. 1993. L-selectin can mediate leukocyte rolling in untreated mesenteric venules in vivo independent of E- or Pselectin. Blood. 82:1632-1638.

13. Lawrence, M. B., and T. A. Springer. 1993. Neutrophils roll on E-selectin. J. Immunol. 151:6338-6346.

14. Gallatin, W. M., I. L. Weissman, and E. C. Butcher. 1983. A cell-surface molecule involved in organ-specific homing of lymphocytes. Nature (Lond.). 303:30-34.

15. Kishimoto, T. K., M. A. Jutila, E. L. Berg, and'E. C. Butcher. 1989. Neutrophil Mac-1 and MEL-14 adhesion proteins inversely regulated by chemotactic factors. Science (Wash. DC). 245:1238-1241.

16. Lewinsohn, D. M., R. F. Bargatze, and E. C. Butcher. 1987. Leukocyteendothelial cell recognition: evidence of a common molecular mechanism shared by neutrophils, lymphocytes, and other leukocytes. J. Immunol. 138:4313-4321.

17. Geng, J., M. P. Bevilacqua, K. L. Moore, T. M. McIntyre, S. M. Prescott, J. M. Kim, G. A. Bliss, G. A. Zimmerman, and R. P. McEver. 1990. Rapid neutrophil adhesion to activated endothelium mediated by GMP-140. Nature (Lond.). 343:757-760.

18. Hsu-Lin, S.-C., C. L. Berman, B. C. Furie, D. August, and B. Furie. 1984. A platelet membrane protein expressed during platelet activation and secretion. J. Biol. Chem. 259:9121-9126.

19. Hatton, R., K. K. Hamilton, R. D. Fugate, R. P. McEver, and P. J. Sims. 1989. Stimulated secretion of endothelial cell von Willebrand factor is accompanied by rapid redistribution to the cell surface of intracellular granule membrane protein GMP-140. J. Biol. Chem. 264:7768-7771.

20. Weller, A., S. Isenmann, and D. Vestweber. 1992. Cloning of the mouse endothelial selectins: expression of both $\mathrm{E}$ - and P-selectin is inducible by tumor necrosis factor $\alpha$. J. Biol. Chem. 267:15176-15183.

21. Bevilacqua, M. P., J. S. Pober, D. L. Mendrick, R. S. Cotran, and M. A. Gimbrone. 1987. Identification of an inducible endothelial-leukocyte adhesion molecule. Proc. Natl. Acad. Sci. USA. 84:9238-9242.

22. Watson, S. R., C. Fennie, and L. A. Lasky. 1991. Neutrophil influx into an inflammatory site inhibited by a soluble homing receptor-IgG chimera. Nature (Lond.). 349:164-167.

23. Dustin, M. L., R. Rothlein, A. K. Bhan, C. A. Dinarello, and T. A. Springer. 1986. Induction by IL-1 and interferon- $\gamma$ : tissue distribution, biochemistry, and function of a natural adherence molecule (ICAM-1). J. Immunol. 137:245-254.

24. Pober, J. S., M. A. Gimbrone, L. A. Lapierre, D. L. Mendrick, W. Fiers, R. Rothlein, and T. A. Springer. 1986. Overlapping patterns of activation of human endothelial cells by interleukin 1 , tumor necrosis factor, and immune interferon. J. Immunol. 137:1893-1896.

25. Rothlein, R., M. L. Dustin, S. D. Marlin, and T. A. Springer. 1986. A human intercellular adhesion molecule (ICAM-1) distinct from LFA-1. J. Immunol. 137:1270-1274.

26. Takei, F. 1985. Inhibition of mixed lymphocyte response by a rat monoclonal antibody to a novel murine lymphocyte activation antigen (MALA-2). $J$. Immunol. 134:1403-1407.

27. Sligh, J. E., C. M. Ballantyne, S. S. Rich, H. K. Hawkins, C. W. Smith A. Bradley, and A. L. Beaudet. 1993. Inflammatory and immune responses are impaired in ICAM-1 deficient mice. Proc. Natl. Acad. Sci. USA. 90:8529-8533.

28. Wilson, R. W., C. M. Ballantyne, C. W. Smith, C. Montgomery, A Bradley, W. E. O'Brien, and A. L. Beaudet. 1993. Gene targeting yields a CD18mutant mouse for study of inflammation. J. Immunol. 151:1571-1578.

29. Muller, W. A., S. A. Wegl, X. Deng, and D. M. Phillips. 1993. PECAM1 is required for transendothelial migration of leukocytes. J. Exp. Med. 178:449460.

30. Vaporciyan, A. A., H. M. DeLisser, H. Yan, I. I. Mendigurer, S. R. Thom, M. L. Jones, P. A. Ward, and S. M. Albelda. 1993. Involvement of plateletendothelial cell adhesion molecule-1 in neutrophil recruitment in vivo. Science (Wash. DC). 262:1580-1582.

31. DeLisser, H. M., P. J. Newman, and S. M. Albelda. 1993. Platelet endothelial cell adhesion molecule (CD31). In Current Topics Microbiology and Immunology. Leukocyte Homing and Differentiation. D. Dunon, C. R. Mackay, and B. A. Imhof, editors. Springer-Verlag, Heidelberg. 37-45.

32. Sanders, W. E., R. W. Wilson, C. M. Ballantyne, and A. L. Beaudet. 
1992. Molecular cloning and analysis of in vivo expression of murine granule membrane protein-140. Blood. 80:795-800.

33. Johnston, G. I., G. A. Bliss, P. J. Newman, and R. P. McEver. 1990 Structure of the human gene encoding granule membrane protein-140, a membe of the selectin family of adhesion receptors for leukocytes. J. Biol. Chem. 265:21381-21385.

34. Kuehn, M. R., A. Bradley, E. J. Robertson, and M. J. Evans. 1987. A potential animal model for Lesch-Nyhan syndrome through introduction of HPRT mutations into mice. Nature (Lond.). 326:295-298.

35. Soriano, P., C. Montgomery, R. Geske, and A. Bradley. 1991. Targeted disruption of the c-src proto-oncogene leads to osteopetrosis in mice. Cell. 64:693-702.

36. McMahon, A. P., and A. Bradley. 1990. The Wnt-1 (int-1) proto-oncogene is required for development of a large region of the mouse brain. Cell. 62:10731085 .

37. Anderson, D. C., and T. A. Springer. 1987. Leukocyte adhesion deficiency: an inherited defect in the Mac-1, LFA-1, and p150,95 glycoproteins. Annu. Rev. Med. 38:175-194.

38. Etzioni, A., M. Frydman, S. Pollack, I. Avidor, M. L. Phillips, J. C Paulson, and R. Gershoni-Baruch. 1992. Brief report: recurrent severe infections caused by a novel leukocyte adhesion deficiency. N. Engl. J. Med. 327:17891792.

39. Frydman, M., A. Etzioni, T. Eiditz-Markus, I. Avidor, I. Varsano, Y. Shechter, J. B. Orlin, and R. Gershoni-Baruch. 1993. Rambam Hasharon syndrome of mental retardation, short-limbed dwarfism, defective neutrophil chemotaxis and Bombay phenotype. Am. J. Med. Genet. 44:297-302.

40. Doerschuk, C. M., R. K. Winn, H. O. Coxson, and J. M. Harlan. 1990 CD18-dependent and independent mechanisms of neutrophil adherence in the pulmonary and systemic microvasculature of rabbits. J. Immunol. 144:23272333.

41. Doerschuk, C. M., J. Markos, H. O. Coxson, D. English, and J. C. Hogg. 1994. Quantitation of neutrophil migration in acute bacterial pneumonia in rabbits. J. Appl. Physiol. 77:2593-2599.

42. Gie, R. P., C. M. Doerschuk, D. English, H. O. Coxson, and J. C. Hogg. 1991. Neutrophil-associated lung injury following the infusion of activated plasma. J. Appl. Physiol. 70:2471-2478.
43. Majno, G., and G. E. Palade. 1961. Studies of inflammation. J. Biophys. Biochem. Cytol. 11:571-605.

44. Schulman, E. S. 1993. The role of mast cells in inflammatory responses in the lung. Crit. Rev. Immunol. 13:35-70.

45. Arfors, K. E., C. Lundberg, L. Lindbom, K. Lundberg, P. G. Beatty, and J. M. Harlan. 1987. A monoclonal antibody to the membrane glycoprotein complex CD18 inhibits polymorphonuclear leukocyte accumulation and plasma leakage in vivo. Blood. 69:338-340.

46. Hellewell, P. G., S. K. Young, P. M. Henson, and G. S. Worthen. 1994 Disparate role of the $\beta_{2}$-integrin CD18 in the local accumulation of neutrophils in pulmonary and cutaneous inflammation in the rabbit. Am. J. Respir. Cell Mol. Biol. 10:391-398.

47. Van Otteren, G. M., T. J. Standiford, S. L. Kunkel, J. M. Danforth, M. D. Burdick, L. V. Abruzzo, and R. M. Strieter. 1994. Expression and regulation of macrophage inflammatory protein-1 $\alpha$ by murine alveolar and peritoneal macrophages. Am. J. Respir. Cell Mol. Biol. 10:8-15.

48. Leake, E. S., D. Gonzales-Ojeda, and Q. N. Myrvik. 1964. Enzymatic differences between normal alveolar macrophages and oil-induced peritoneal macrophages obtained from rabbits. Exp. Cell Res. 33:553-561.

49. Mileski, W., J. Harlan, C. Rice, and R. Winn. 1990. Streptococcus pneumoniae-stimulated macrophages induce neutrophils to emigrate by a CD18-independent mechanism of adherence. Circ. Shock. 31:259-267.

50. Winn, R. K., and J. M. Harlan. 1993. CD18-independent neutrophil and mononuclear leukocyte emigration into the peritoneum of rabbits. J. Clin. Invest. 92:1168-1173.

51. Downey, G. P., G. S. Worthen, P. M. Henson, and D. M. Hyde. 1993. Neutrophil sequestration and migration in localized pulmonary inflammation. Am. Rev. Respir. Dis. 147:168-176.

52. Doerschuk, C. M., N. Beyers, H. O. Coxson, B. Wiggs, and J. C. Hogg 1993. Comparison of neutrophil and capillary diameters and their relation to neutrophil sequestration in the lung. J. Appl. Physiol. 74:3040-3045.

53. Burns, A. B., F. Takei, and C. M. Doerschuk. 1994. Quantitation of ICAM1 expression in mouse lung during pneumonia. J. Immunol. 153:3189-3198.

54. Mulligan, M. S., M. J. Polley, R. J. Bayer, M. F. Nunn, J. C. Paulson, and P. A. Ward. 1992. Neutrophil-dependent acute lung injury. Requirement for P-selectin (GMP-140). J. Clin. Invest. 90:1600-1607. 